\title{
Perceptions of Persons With Type 2 Diabetes Treated in Swedish Primary Health Care: Qualitative Study on Using eHealth Services for Self-Management Support
}

Ulrika Öberg $^{1,2}$, RN, MSc; Ulf Isaksson ${ }^{1,2}$, MHN, PhD; Lena Jutterström ${ }^{1}$, RN, PhD; Carl Johan Orre ${ }^{3}$ PhD; Åsa Hörnsten ${ }^{1}, \mathrm{RN}, \mathrm{PhD}$

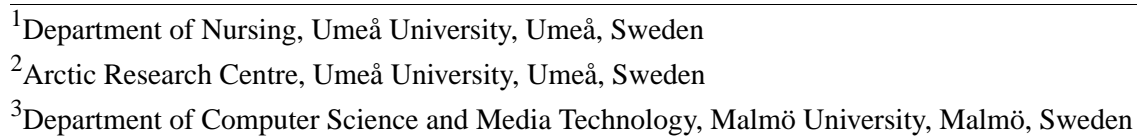

\section{Corresponding Author:}

Ulrika Öberg, RN, MSc

Department of Nursing

Umeå University

The Caring Sciences Building

Umeå, 90187

Sweden

Phone: 46907866374

Email: ulrika.oberg@umu.se

\section{Abstract}

Background: Digital health services are increasing rapidly worldwide. Strategies to involve patients in self-monitoring of type 2 diabetes (T2D) on a daily basis is of crucial importance, and there is a need to optimize the delivery of care such as self-management support. Digitalized solutions have the potential to modify and personalize the way in which people use primary health services, both by increasing access to information and providing other forms of support at a distance. It is a challenge to integrate core values of person-centered care into digitalized health care services.

Objective: The objective of this study was to describe perceptions of using electronic health (eHealth) services and related technologies for self-management support among people with T2D treated in Swedish primary health care.

Methods: This is a qualitative study based on interviews analyzed using qualitative content analysis conducted among people diagnosed with T2D.

Results: Findings suggest that the participants had mixed feelings regarding the use of digital health services for self-management support. They experienced potentials such as increased involvement, empowerment, and security, as well as concerns such as ambivalence and uncertainty.

Conclusions: Digital health services for self-management are easily accessible and have the potential to reach a wide population. However, targeted training to increase digital skills is required, and personalized devices must be adapted and become more person-centered to improve patients' involvement in their own care.

(JMIR Diabetes 2018;3(1):e7) doi: 10.2196/diabetes.9059

\section{KEYWORDS}

eHealth; internet; type 2 diabetes; self-management; primary health care; qualitative research

\section{Introduction}

Information and communication technology (ICT) for health promotion, disease prevention, and disease management used in health care (electronic health, eHealth) is suggested to have a great potential to improve access, quality, safety and efficiency of care, and further prevention, diagnostics, treatment, and self-management among people with chronic illnesses such as type 2 diabetes (T2D) [1-3]. Until about a decade ago, the idea of allowing a digital device to play a decisive role in how T2D is controlled and monitored was unthinkable. Today, it is booming in health care with a rapid growth and supply of various applications and interactive systems aimed at improving 
people's health behavior and supporting self-management in chronic illness [4].

People with T2D and their perceptions of using digital health services and related technology is the objective of this study. Digital health services or eHealth are terms that are used interchangeably in this paper. In these terms, we include using the internet for medical and health information and self-management support via, for example, diabetes websites, using patient portals, blogs, chat rooms, and forums. Furthermore, telehealth, telemedicine, telemonitoring, mobile Health (mHealth), apps, electronic health records, and other uses of digitization could be involved. These technologies are important since they are supposed to provide, improve, and support self-management and the delivery of care at a distance.

Even if developments and implementations of ICT in health care proceed quickly, opinions about the efficiency of eHealth vary among both patients and health care professionals [5-7]. This is a challenge as the use of innovative technologies in health care is not possible without the acceptance of patients and health care professionals. To support people with chronic illness to more readily accept digital health services and to gain the ability and knowledge to use ICT, we need to learn more from these groups of users [8,9]. In this paper, the focus is on people with T2D. One reason is that the prevalence of T2D is increasing with considerable morbidity and mortality, generating a heavy burden both at a personal level and at the health care system in both developed and developing countries [10,11]. In Sweden, it is estimated that $4 \%$ to $6 \%$ of the population has T2D with mean age for diagnosis of about 63 years. [12].

Self-management is a basic and integrated part of the treatment in T2D. Since it is a progressive disease, it must be complemented with oral antidiabetic agents or insulin injections over time, which could add to the burden of the disease [13-15]. To control the disease progression, people with T2D visit physicians and specialist nurses several times per year to take various tests, adjust medication, and get self-management support aimed at postponing severe complications [16]. People with T2D commonly struggle with complex self-management activities, including healthy eating, physical activity, blood sugar testing, self-monitoring, and medications [17,18]. Therefore, to manage diabetes efficiently on a daily basis over time, person-centered and tailored education and support, as well as collaboration or partnership between patients and health care professionals is recommended [13,19,20].

The various technologies used in digital health services such as the internet, mobile apps, and other kinds of interactive digital tools and devices in health care have a potential to facilitate self-management, which in turn may prevent or postpone disease complications in a chronic disease [21-25]. From an economic perspective, eHealth may lead to better cost-efficiency in the health sector [26], and it has a potential to complement or even substitute several personal contacts with health care professionals [27].

Implementation of ICT is recommended in Swedish health care. The government's vision is clear-Sweden is to be the best in the world in eHealth by 2025, and this has to be realized by using the potential of digitization and eHealth to help people achieve good and equal health and well-being, as well as develop and strengthen their own resources for increased independence and participation in society [28]. Furthermore, the use of eHealth technology is recommended for both professionals and patients, but also that the care should be person-centered [28-30]. A challenge though is to integrate goals of person-centered care (PCC) in the implementation of digitized self-management support [5]. One core value in PCC is the development of a mutual and respectful partnership between patients and health care professionals. Another is that care plans should be based on patients' narratives, where a comprehensive view of the patients and autonomy is of great importance [31]. How these core values could be integrated into eHealth-based self-management support in practice is not clearly expressed in policy documents.

Preferences for use of eHealth devices for health information are higher among younger people, while persons 70 years and older, are reported to prefer nondigital modalities for health information even if they are internet users [32]. Furthermore, among adult internet users, differences are reported where women are reported to use eHealth devices more frequently than men. There are also differences based on socioeconomic status (SOS) in favor for those with higher SOS, but no differences based on ethnicity [33]. In T2D, a main barrier has been reported to be lack of access to the internet and poor user-friendliness of Web applications. People with T2D in need of care are reported to be more engaged in long-term use of eHealth devices such as Web applications [34]. People with different diseases may also express different needs and expectations toward self-management and eHealth for self-management purposes. In a study by Huygens et al [35], participants reported that eHealth should not replace but complement personal care. They also reported feelings of anxiety and uncertainty about follow-up of deviant measurements. From Sweden, we have not found any studies regarding perceptions or expectations on use of eHealth devices for self-management support in T2D. The objective of this study was, therefore, to describe perceptions of using eHealth services and related technologies for self-management support among people with T2D treated in Swedish primary health care.

\section{Methods}

\section{Overview}

This study is part of a larger randomized intervention project aimed at designing and implementing person-centered interactive self-management support (iSMS) in primary health care in northern Sweden. The overall project has a cocreation design, and participants' perceptions are therefore of great value for designing a forthcoming intervention that is registered at ClinicalTrials.gov (NCT03165084).

\section{Participants and Setting}

The participants were treated in primary health care in a county in northern Sweden. Inclusion criteria in this study were Swedish-speaking individuals diagnosed with T2D. In total, 11 people ( 3 women, 8 men) aged from 50 to 78 years (median 65 years) were interviewed. 
The purpose was to reach a purposeful sample with an even gender distribution, but it was difficult to recruit women in the study. The duration of T2D among the participants varied from 4 months up to about 10 years. Of these 11 participants, 7 participants lived together with a partner, while 4 were single. Each participant owned a smartphone. Initially, the aim of the study was presented by the first author at an information meeting held at the Local Diabetes Association, where 4 participants declared their interest in participating. A snowball selection was then used to include the remaining 7 participants into the study, that is, enrolled participants suggested names of other people who could be contacted for interviews.

\section{Data Collection}

The first author conducted interviews with the participants individually, either in their homes $(n=8)$ or at the university $(n=3)$ during 2016. All participants were contacted in person or by telephone in advance. They received information about the study, and date and place for the interview were decided. At the interview session, each interviewee was informed again and had the opportunity to ask questions or withdraw participation. The interviews performed by the first author lasted between 40 and 80 (median=60) $\mathrm{min}$ and were digitally recorded. During the interview, a semistructured interview guide was used, as well as an ambition to get answers that were narrative in nature. The opening question was, "If I say information technology and eHealth, what do you think of?" Examples of other questions were as follows:

- "Can you please tell me about your experiences of using digital health services in contacts with care?"

- "Have you ever used any digital technology device in your diabetes self-management? Please, tell me about those experiences."

Probing questions and prompts were used to deepen the topics and to get answers on issues not already mentioned.

\section{Data Analysis}

The interview data were transcribed verbatim by the first author and analyzed using qualitative content analysis as described by Graneheim and Lundman [36]. Qualitative content analysis is a systematic way to describe variations of content in a verbal or written communication [36,37]. The epistemological basis of qualitative content analysis is that data and interpretation are cocreations between the interviewee and the interviewer, and interpretation during the analysis phase is a cocreation of the researchers and the text [38,39]. The analysis was performed in several steps. First, all text was read through thoroughly to get a sense of the whole. This reading revealed 2 overarching domains-Potentials and Concerns - into which the text was sorted. The text in each domain was then divided into meaning units consisting of words or sentences related to each other through their content and context.

The identified meaning units were then condensed, that is, made shorter without losing the core meaning, and interpreted and labeled with codes. The codes were sorted, based on similarities and dissimilarities, into 12 subcategories within the 2 domains. The subcategories were then abstracted to 5 categories as follows:
- Potentials

- Involvement

- Independence

- Responsibility

- Empowerment

- Knowledge

- Participation

- Engagement

- Freedom

- Security

- Confidentiality

- Privacy

- Concerns

- Ambivalence

- Insufficient support

- Lack of digital skills

- Uncertainty

- Distrust of information

- Unreliability

Following the steps of the analysis should not be seen as a linear process, rather a process of going back and forth between the steps and between original data and analyzed data. All authors also discussed the interpretations within every step of the analysis until consensus was achieved [36].

\section{Ethical Considerations}

The Regional Ethical Review Board at Umeå University approved the study (Dnr 2014-179-31M) and was conducted according to the ethical principles described in the Helsinki Declaration [40]. Before giving informed consent, the participants received oral and written information. It was emphasized that participation was voluntary and that they could withdraw from the study at any time without giving explanation; they were also assured of confidentiality. The transcripts were made anonymous by removing personal information. In addition, quotations were made anonymous with small changes in wordings that did not alter their core meaning.

\section{Results}

A total of 5 categories within the domains Potentials and Concerns were identified in the analysis. The results were divided into 2 domains, 5 categories and 12 subcategories. Each subcategory is further enlightened by quotations from the original interviews in the following text.

\section{Potentials}

Within the domain Potentials, which referred to the positive perceptions of using digital health services as self-management support, the categories Involvement, Empowerment, and Security were highlighted.

\section{Involvement}

The importance of being involved in decisions about medication and in discussions about self-management and goals-for example, blood sugar levels-were highlighted. Some had 
negative perceptions from previous health care contacts when health care professionals made decisions "over their heads." The subcategories related to this category are Independence and Responsibility.

\section{Independence}

Independence included striving to handle all demands related to the disease and was expressed as being natural. However, sometimes, social demands made it difficult to remember or prioritize self-management. Using digital health services was described as a key to try harder and as something positive. Some were willing to pay for digital and technological tools that could provide insights and motivation to self-manage their chronic condition:

I use and have paid for an app on my smartphone, so I can monitor my weight, daily steps and of course my blood sugar. I love it.

\section{Responsibility}

The importance of taking responsibility for oneself was highlighted. Those who had used various digital health services previously expressed that it helped them to take more action in their self-management. However, this was something they kept secret and did not always tell their diabetes nurse, since she might apprehend it as being critical of her advice. They also forced the importance of being seen as capable and responsible by the diabetes nurse, something that included that they accepted the consequences of even unhealthy choices. These participants had often got the advice from their diabetes nurses not to trust information on the internet and felt that using apps was in a gray zone, almost forbidden. Nevertheless, the participants described how it had helped them:

\section{It [the app] helped me to take responsibility for a healthier behaviour; I believe I became more confident in myself since I started to use it. Much more than when I got my diabetes diagnosis.}

\section{Empowerment}

A number of areas related to eHealth were found important for the management of the participants' own health. They viewed applications and digital tools as powerful aids for understanding and becoming more aware, which enabled them to take control of their disease. Tracking their symptoms and treatments using diabetes apps and participation in online forum discussions provided them comfort. They learned of peers from online support groups by sharing what symptoms helped them take steps to adjust living with T2D, what types of treatment they used, and how this worked to strengthen them. As well-informed patients, they could more easily discuss and request different treatments with health care providers. The subcategories related to this category are Knowledge, Participation, Engagement, and Freedom.

\section{Knowledge}

Increased knowledge was highlighted as an important goal for managing T2D. The participants expressed that they preferred better collaboration between themselves and health care professionals. They saw themselves as knowledgeable, capable, and responsible for their own health and self-management. Now, knowledge enabled them to make informed choices, which could lead to better control, something the use of apps could facilitate. Gaining knowledge at one's own pace was seen as a benefit.

\section{I can get the knowledge I want about type 2 diabetes [on the internet], and make up my own goals, step by step at my own pace [using an app]...without having to discuss everything with the diabetes nurse.}

\section{Participation}

Digital health services were perceived as providing opportunities for increased participation, since they could discuss their condition with people other than health care professionals. Some gave examples of their adult children's increased participation when they lived far away. Using a mobile app that supported management of diabetes, the adult children could be updated online and follow the illness process at a distance. They could also easily get in touch with people with diabetes who they could contact through various Web-based portals for patients:

\section{I especially enjoy being able to reason with others with the same problems on different patient forums. It is a kind of social networking, though I do not leave home often...}

\section{Engagement}

Digital health services and devices made the participants more engaged through an increased awareness about the disease and needs for improved self-management. It was described that they traditionally met a doctor and a nurse semiannually. Between those visits, the disease-related information was easy to "forget," and thereby they did not focus on changing habits. Due to an increased use of digital devices, they viewed personal visits at the health care center as unnecessary:
I feel more engaged now [using an app for self-monitoring]...I don't always have to visit the primary health centre if I have problems, some things can be solved through eService on the primary healthcare centres website...

\section{Freedom}

Using digital health services was expressed as increasing the participants' freedom. They gave examples of the freedom that was related to 24-hour service online. They did not have to wait until the next morning or a Monday, when the diabetes nurse was available if they had problems or had questions during the weekend:

Anytime during all hours I have the freedom to reflect
and get feedback [from patient forums] on my
thoughts. I do not have to wait until the next day when
the primary healthcare centre opens as I did before.

\section{Security}

Digital health service was experienced as offering security. Safeguard components as passwords, encryption systems such as an e-ID (BankID or Mobile BankID), and similar technical safeguards for authorization or access controls strengthened the view of technology as something positive that protected the 
participants. The subcategories related to the category Security are Confidentiality and Privacy.

\section{Confidentiality}

The participants expressed worries and concerns about the following: that people from their community could witness them visiting the primary health care center and this could endanger their confidentiality. It could have personal consequences if information about them, known by neighbors, could get leaked to health care professionals, for example, about their families and social circumstances not known by a health care professional. In the next step, this information could get leaked to employers or maybe insurance companies. Sometimes they withheld information from health care professionals because of confidentiality concerns and also could avoid personal visits to the health care center. Web-based health care services were described as more secure, with personal log-ins, which was seen as trustworthy, and were at times perceived as better than the traditional face-to-face visits:

I trust that all information about me is kept confidential, even if it is online...but I do not know if I can trust that only authorised persons at the healthcare centre have access to my medical records...I mean, my neighbour works there as a secretary...

\section{Privacy}

It was highlighted that when digitized health is discussed in the media or in popular scientific literature, the ethics, security, and privacy risks are often questioned. Despite this, the participants were not worried. Instead, they expressed that lack of privacy was a barrier to visiting health care centers in small communities. Participants mentioned breaches of their privacy and had experienced that fellow patients took mobile photos in the waiting room and put them on Facebook. Using Web-based health services, they did not have to "advertise" their problems to other patients in the waiting room, and thereby, they did not feel as vulnerable and exposed:

When I sit in the waiting room, I could find it problematic to meet neighbours and others. I don't want to expose myself as an ill person to them...I think I would prefer online meetings with my nurse.

\section{Concerns}

Within the domain Concerns, which referred to the more negative side of the participants' perceptions of using digital health services for self-management support, the categories Ambivalence and Uncertainty were highlighted.

\section{Ambivalence}

The participants expressed ambivalence concerning using digital health services and digital devices such as apps or iSMS. Mostly, it concerned feelings of lacking confidence and not being able to manage the technology. Furthermore, they had too little training, wanted support, and therefore avoided digital devices if they could. The subcategories related to the category Ambivalence are Insufficient Support and Lack of Digital Skills.

\section{Insufficient Support}

Being afraid of the new technologies as well as having limited or insufficient technological support increased the risk of not getting the medical advice participants needed. They therefore preferred face-to-face meetings with health care professionals. They did not have any family members or friends who could support them, and therefore, they were afraid of having technical problems.

\section{What if something goes wrong?}

\section{Lack of Digital Skills}

Participants expressed an ambivalence and reluctance toward using digital technology. The reason was expressed as having a lack of digital competence and skills. They also mentioned poor technological design as a barrier to navigate websites and apps. Participants stated that they had difficulties using their smartphones due to physical problems such as sight loss or tremor.

\section{It's too difficult to use for me, I can't even type [on the smartphone].}

\section{Uncertainty}

Digital systems in general were questioned by participants. They felt uncertain whether they could trust information they came across on the internet, and they were afraid of problems with eHealth services due to unreliable internet connections. The subcategories related to the category Uncertainty are Distrust of Information and Unreliability.

\section{Distrust of Information}

Participants saw no value in using technology to manage their health. Furthermore, they did not always trust the quality and authenticity of the information on websites they found and whether these websites provided accurate and detailed information about diabetes management. It was considered unsafe to rely entirely on the Web-based information that was available since the content could be medically incorrect and potentially endanger their health.

\section{I mean, how can I be $100 \%$ sure that the information online is correct? It could be fatal.}

\section{Unreliability}

Participants highlighted the unreliable and unstable connections, both on wired or wireless broadband with an internet turning on and off rapidly and slow when working. They also said that the lack of internet access through wired or wireless broadband technologies in their homes made it impossible to rely on and use the computer or smartphone for eHealth purposes. Participants expressed that even the primary health care service could not guarantee reliable computer systems:

What if there's a system failure due to a crash or virus, and there will be loss of data? Or an unstable connection? Can the system be really secure? 


\section{Discussion}

\section{Principal Findings}

This study has provided insight about the perceptions that people with T2D may have about using ICT and digital health services for self-management support, and the findings show that the participants are mainly positive, but they have mixed feelings regarding use of eHealth services and digital devices irrespective of whether it concerned a Web or mobile app. On one hand, they experienced potentials such as increased involvement, empowerment, and security; on the other hand, they expressed concerns such as ambivalence and uncertainty. One explanation for the variation in perceptions of using digital health services or eHealth services for self-management support could be the participants' differing capabilities such as education and computer training and experience. From literature we know that age, gender, as well as SOS situations influence people's perceptions [32-34].

Several studies report that eHealth is promising with regard to self-management support and that people with chronic conditions desire tools that effectively reduce the limitations of life caused by disease [41-43]. Alpay et al [44] concluded that by removing barriers of time and geographical distance in health care services - using digital and technological services such as video consultations and telehealth - the patients gain flexibility. They get an easier and more convenient access to health care, they may even have fewer time-demanding health care center visits, and finally, patients can receive care at a location that does not require transportation and in an environment that can be experienced as less threatening.

Regarding the category Involvement, our results highlight that self-monitoring may increase patients' independence. Similar results are reported by Holtz and Lauckner [45], and by Alvarado et al [46], who showed that people with diabetes could adapt easier to their condition by using their mobile phones in self-monitoring and management of diabetes. Kruis et al [47] presented that innovative eHealth self-management solutions can support or improve independence among people with chronic conditions. Ahern et al [48] concluded that the potential of patient technologies can only be accomplished by motivating patients to become more engaged and responsible for their own care. In a study by Nijland et al [42], the authors argued that interactive eHealth applications must be continuously changed and developed to promote individual self-care, through feedback and exchange of information, something that is in line with the value of independence. Interactive eHealth tools designed to provide feedback on patients' self-monitoring appear to engage patients the most, since personalized and interactive features stimulate active participation by both patients and nurses. Nijland et al [42] reported that the diabetes patients in their study felt better monitored by the feedback they received and were therefore more motivated to take a more active role in the self-management of their illness - something that also led to increased independence.

Regarding the category Empowerment, our results suggest that use of interactive eHealth platforms seems to have a potential to increase patient empowerment through increased knowledge, participation, engagement, and freedom. Our findings support previous studies that report that empowerment can be improved using digitized approaches in health care [5,44,49]. Empowerment implies participation and responsibility through increased awareness and knowledge [50,51]. Self-efficacy is an important aspect of empowerment and relates to change in behavior, which is important for self-management in chronic conditions [52]. Patient empowerment and PCC are closely related complementary concepts. These do not oppose each other, and indeed patient empowerment can be achieved through PCC [53]. Both patient empowerment and PCC are emphasized by health researchers and policy makers and expressed in care policy documents nationally and internationally $[7,20]$. Furthermore, it has been suggested that PCC increases patient outcomes and satisfaction in chronic illnesses [54,55] and T2D [54]. Thus, using the Web for medical and health facts is an approach in health care that can support empowerment and is facilitated by a shift to PCC that can subsequently improve self-management [25,30,55,56]. Digitized access increases patient empowerment and enables them to participate more actively in making better informed choices regarding their health in interaction with health care. Technological advances for self-monitoring are changing the conditions for chronic disease management. The use of different communication tools and interactive platforms may improve patient participation in decision making and facilitate for patients to communicate easily with health care professionals [49,57]. Medical and health information on the internet, digital health that patients use as in-home monitoring, virtual consultations, and mobile apps are also available to users 24 hours a day, 7 days a week [58] to provide alternatives to them apart from the primary health care centers, and this gives a certain degree of freedom [59]. However, a benefit for health care professionals using digitalized technology in self-management support is the option to be in contact with patients more frequently than semiannually or annually, as is common today $[60,61]$.

Regarding the category Security, our results shows that participants in this study experienced that use of Web-based technology was seen as something safe and reduced privacy exposures, which is confirmed by other studies $[62,63]$. Participants were not bothered much about security concerns; they trusted that the different technical safeguards, such as passwords or encryption systems, were safe enough. Similar results are reported by Spanakis et al [63] who stated that most patients seem to be willing to disclose information relevant to their condition to their health provider, with no particular awareness of how the patient information is transferred. The use of digital health services can also reduce the number of visits to the health care centers, something that can be experienced as stressful, time-consuming, and expensive. Fewer face-to-face visits might also imply changes in the patients' perception of self-management support as well as reconfiguring work activities for the diabetes nurse [64]. Encouraging patients to share their self-monitored data with the diabetes nurse to a higher degree may become a trade-off for fewer visits, thus having health economic implications. This is in line with a study by Eland-de Kok et al [65] who showed that adapted and person-centered support increased more than semiannual visits. This may lead to quality improvements and a higher priority 
for those patients who need face-to-face visits the most. A literature review by Hardiker and Grant [66] showed that the use of different Web-based services depended on a number of factors such as the characteristics of users, the kinds of technological issues, characteristics of the digital health services social aspects of users, and the digitized services in use. This requires health care professionals to concentrate their efforts where they are needed most, by tailoring services to meet the needs of a broad range of users.

Regarding the category Ambivalence, our results highlight that some of the participants stressed concerns regarding, for example, lacking digital skills and knowledge about how to use digital health services, which is in line with other studies $[67,68]$ that have also reported an existing age-related digital division. This division concerns everything from the design of the digital device and screen design to complex commands and procedures, including inadequate training and instructions that can prevent older people from interacting with digital systems. Czaja and Lee [67] reported that predictors of not using digitized technology were primarily the very old with cognitive decline associated with different aging processes such as vision impairment, and attitudes such as anxiety about computer use and the perception that technology is not useful to them, both of which are compatible with our results. Usually participants in our study were also reluctant about using digital health services and preferred face-to-face meetings with health care professionals. Similar results are reported by Currie et al [27] who conclude that digitized solutions are not the key for every patient and thus do not have the same impact as a face-to-face meeting with health care professionals, since they may create feelings of loss of proximity for some patients. The lack of proximity in digital health services is also highlighted in other studies and is a challenge to overcome. Video consultations could sometimes compensate for the lack of proximity in digitized meetings [69,70]. Technological barriers could therefore be solved and personalized to meet the needs of those who have physical barriers such as cognitive, sensory, and motor deficits.

Regarding the category Uncertainty, our results highlighted that participants were ambivalent about their views of the reliability and quality of Web-based digital health information. Similar findings report individuals having difficulties using the internet to find complete and proper information concerning health issues. Not relying on Web-based information in making decisions about treatment and self-management, including whether or not to seek care, may negatively influence the user's decisions [71,72]. In Sweden, 93\% of the population have access to the internet at home, and outside the home, $71 \%$ connect to the internet using mobile phones or smartphones. Although access to internet is high in Sweden among the people aged 16 to 85 years, still $7 \%$ of households in Sweden do not have access to the internet. Those who have never used the internet are found mostly in the age group 75 to 85 years [73]. Even if Sweden is a country with very high internet access, we have interpreted limited access to internet connections or broadband as a factor that affects the usefulness of digital health services. This is concurrent with Currie et al [27] who reported problems for patients living in rural areas compared with those living in urban areas concerning the use of technology for health purposes. They highlighted challenges related to slow and unreliable broadband services. Fuji et al [74], on the other hand, conclude that instead of primarily focusing on issues concerning internet infrastructure or a lack of internet access in rural areas, focus should be placed on overcoming other concerns and barriers among the users.

Our results could guide such development. The result also indicates that future digital health solutions preferably should have high demands on functionality, personalization, and an easy-to-use design to be user-friendly. Self-monitoring and measurements should also be smooth to integrate with the health care records and communication channels. Furthermore, a "universal" digital solution does not exist. One size rarely suits everyone. To improve user customization, people with T2D from various socioeconomic backgrounds, gender, and ages need to be involved in the development of future digital tools.

\section{Strengths and Limitations}

The findings in this qualitative study cast some light on the experiences of using various digital health services in self-management support among people with T2D treated in Swedish primary health care. We view our results as transferable to other groups of patients with similar lifestyle-related chronic conditions in societies similar to Sweden. However, according to Graneheim and Lundman [36], it is up to the reader's judgment as whether or not the reported findings are transferable to other contexts.

We recruited 11 people with T2D for individual interviews, using a combination of purposive and subsequent sampling [75], which made it possible to expand the group of participants. However, there is a risk of bias, since our sample may consist of participants with an interest in eHealth. Despite that, our result pointed to a variation of perceptions about the use of eHealth services and could thereby be useful.

The majority of the participants were men, and the age range was 50 to 74 years. It is possible that the outcome of this study would have been different if more women had been included and if the age range had been different, including, for example, very old patients. Nevertheless, the participants in this study are representative of people with T2D and provided rich data.

There are no rules for how large the selection of participants should be in qualitative research methodology, but the selection is generally determined by the need for information data. In this case, it was considered that it had come to the stage where further data collection would not provide more knowledge and that the collected data was sufficient for the study. The saturation point was judged as reached. The term saturation derives from grounded theory, but it is also used in other qualitative approaches [76].

The interviews were conducted by the first author alone. However, all authors listened to and discussed the interviews and then were involved in interpretations at every step of the analytical process, something we believe has strengthened the trustworthiness of the study and resulted in a consolidation of the findings. 


\section{Conclusions}

The results from this study indicate that persons with T2D have diverse perceptions on using digital health technologies and eHealth services for self-management support. They are interested in digital health technologies and services for self-management support, however, ambivalence was also expressed. Our findings indicate that targeted training and support is needed to overcome barriers and that utilized devices for good reason should be personalized or carefully adapted to the specific situations at hand.
The use of digital health technologies for person-centered self-management support is challenging but can-if implemented appropriately-lead to increasing patient responsibility for their own health and strengthen patients' empowerment and self-management capabilities. Although digital health technologies of today allow for innovative approaches, there are also ethical aspects to consider when new digital health tools or solutions and eHealth services are introduced in health care. Some people may neither wish to nor be able to use digital technology for various reasons on their own, whereas others see it as an important complement to or even substitute for the traditional health care visits.

\section{Acknowledgments}

The authors would like to thank the Swedish Diabetes Association, and the Department of Nursing and the Faculty of Medicine, Umeå University, for providing funding for this study. The authors would especially like to thank the participants for allowing them to make home visits for interviewing and for their contribution to the study. The authors would also like to thank Håkan Larsson and Christina Harrefors, who gave important input to the study in the design and planning phase.

\section{Authors' Contributions}

UÖ recruited participants and performed data collection and transcription. UÖ and $\AA \mathrm{H}$ contributed to the main analysis and interpretation of data. UÖ drafted the first version of the manuscript. UÖ, CJO, LJ, UI, and $\AA$ H contributed in editing the manuscript, and all authors contributed and approved the final version of the manuscript.

\section{Conflicts of Interest}

None declared.

\section{References}

1. Vandelanotte C, Müller AM, Short CE, Hingle M, Nathan N, Williams SL, et al. Past, present, and future of eHealth and mHealth research to improve physical activity and dietary behaviors. J Nutr Educ Behav 2016 Mar;48(3):219-28.e1. [doi: 10.1016/j.jneb.2015.12.006] [Medline: 26965100]

2. Oh H, Rizo C, Enkin M, Jadad A. What is eHealth (3): a systematic review of published definitions. J Med Internet Res 2005 Feb 24;7(1):e1 [FREE Full text] [doi: 10.2196/jmir.7.1.e1] [Medline: 15829471]

3. Eysenbach G. What is e-health? J Med Internet Res 2001;3(2):E20 [FREE Full text] [doi: 10.2196/jmir.3.2.e20] [Medline: 11720962]

4. Rollo ME, Aguiar EJ, Williams RL, Wynne K, Kriss M, Callister R, et al. eHealth technologies to support nutrition and physical activity behaviors in diabetes self-management. Diabetes Metab Syndr Obes 2016;9:381-390 [FREE Full text] [doi: 10.2147/DMSO.S95247] [Medline: 27853384]

5. Dedding C, van Doorn R, Winkler L, Reis R. How will e-health affect patient participation in the clinic? A review of e-health studies and the current evidence for changes in the relationship between medical professionals and patients. Soc Sci Med 2011 Jan;72(1):49-53. [doi: 10.1016/j.socscimed.2010.10.017] [Medline: 21129832]

6. Fagerström C, Tuvesson H, Axelsson L, Nilsson L. The role of ICT in nursing practice: an integrative literature review of the Swedish context. Scand J Caring Sci 2017 Sep;31(3):434-448. [doi: 10.1111/scs.12370] [Medline: 27507258]

7. Vardanalys. 2012. Patient-centeredness in Sweden's health system URL: https://www.vardanalys.se/rapporter/ patient-centeredness-in-swedens-health-system/ [accessed 2018-02-19] [WebCite Cache ID 6xMGkLPgb]

8. Hesse BW, Hansen D, Finholt T, Munson S, Kellogg W, Thomas JC. Social participation in health 2.0. Computer (Long Beach Calif) 2010 Nov 11;43(11):45-52 [FREE Full text] [doi: 10.1109/MC.2010.326] [Medline: 21379365]

9. Hutchesson MJ, Rollo ME, Krukowski R, Ells L, Harvey J, Morgan PJ, et al. eHealth interventions for the prevention and treatment of overweight and obesity in adults: a systematic review with meta-analysis. Obes Rev 2015 May;16(5):376-392. [doi: 10.1111/obr.12268] [Medline: 25753009]

10. World Health Organization. Switzerland Global report on diabetes URL: http://apps.who.int/iris/bitstream/10665/204871/ 1/9789241565257_eng.pdf [accessed 2018-02-19] [WebCite Cache ID 6xMH3T9xZ]

11. American Diabetes Association. Standards of medical care in diabetes-2016 abridged for primary care providers. Clin Diabetes 2016 Jan;34(1):3-21 [FREE Full text] [doi: 10.2337/diaclin.34.1.3] [Medline: 26807004]

12. The Swedish National Diabetes Register. 2016. The Swedish National Diabetes Register (NDR) serves as a useful tool for providers of everyday care URL: https://www.ndr.nu/\#/english [accessed 2018-02-20] [WebCite Cache ID 6xMHNASHW]

13. American Diabetes Association. Standards of medical care in diabetes-2015 abridged for primary care providers. Clin Diabetes 2015 Apr;33(2):97-111 [FREE Full text] [doi: 10.2337/diaclin.33.2.97] [Medline: 25897193] 
14. Inzucchi SE, Bergenstal RM, Buse JB, Diamant M, Ferrannini E, Nauck M, et al. Management of hyperglycemia in type 2 diabetes, 2015: a patient-centered approach: update to a position statement of the American Diabetes Association and the European Association for the Study of Diabetes. Diabetes Care 2015 Jan;38(1):140-149. [doi: 10.2337/dc14-2441] [Medline: 25538310]

15. Powers MA, Bardsley J, Cypress M, Duker P, Funnell MM, Fischl AH, et al. Diabetes self-management education and support in type 2 diabetes: a joint position statement of the American Diabetes Association, the American Association of Diabetes Educators, and the Academy of Nutrition and Dietetics. Diabetes Educ 2015 Aug;41(4):417-430. [doi: 10.1177/0145721715588904] [Medline: 26047627]

16. Gudbjörnsdottir S, Cederholm J, Nilsson PM, Eliasson B, Steering Committee of the Swedish National Diabetes Register. The National Diabetes Register in Sweden: an implementation of the St. Vincent Declaration for Quality Improvement in Diabetes Care. Diabetes Care 2003 Apr;26(4):1270-1276. [Medline: 12663609]

17. Povey RC, Clark-Carter D. Diabetes and healthy eating: a systematic review of the literature. Diabetes Educ 2007;33(6):931-59; discussion 960-1. [doi: 10.1177/0145721707308408] [Medline: 18057263]

18. American Diabetes Association. Standards of medical care in diabetes--2009. Diabetes Care 2009 Jan;32(Suppl 1):S13-S61 [FREE Full text] [doi: $\underline{10.2337 / d c 09-S 013]}$ [Medline: $\underline{19118286}$ ]

19. Swedish National Board of Health and Welfare. 2015. Diabetes care - recommendations, assessments and summary [Diabetesvård - Rekommendationer, bedömningar och sammanfattning] URL: http://www.socialstyrelsen.se/Lists/ Artikelkatalog/Attachments/19687/2015-2-1.pdf [accessed 2018-02-20] [WebCite Cache ID 6xMILqtvx]

20. Inzucchi SE, Bergenstal RM, Buse JB, Diamant M, Ferrannini E, Nauck M, American Diabetes Association (ADA), European Association for the Study of Diabetes (EASD). Management of hyperglycemia in type 2 diabetes: a patient-centered approach: position statement of the American Diabetes Association (ADA) and the European Association for the Study of Diabetes (EASD). Diabetes Care 2012 Jun;35(6):1364-1379 [FREE Full text] [doi: 10.2337/dc12-0413] [Medline: 22517736]

21. Khansa L, Davis Z, Davis H, Chin A, Irvine H, Nichols L, et al. Health information technologies for patients with diabetes. Technol Soc 2016;44:1-9 [FREE Full text] [doi: 10.1016/j.techsoc.2015.11.001]

22. Evers KE. eHealth promotion: the use of the internet for health promotion. Am J Health Promot 2006;20(4):1-7. [Medline: 16555803]

23. Pal K, Eastwood SV, Michie S, Farmer A, Barnard ML, Peacock R, et al. Computer-based interventions to improve self-management in adults with type 2 diabetes: a systematic review and meta-analysis. Diabetes Care 2014 Jun;37(6):1759-1766. [doi: 10.2337/dc13-1386] [Medline: 24855158]

24. Riazi H, Larijani B, Langarizadeh M, Shahmoradi L. Managing diabetes mellitus using information technology: a systematic review. J Diabetes Metab Disord 2015;14:49 [FREE Full text] [doi: 10.1186/s40200-015-0174-x] [Medline: 26075190]

25. Steele GC, Gill A, Khan AI, Hans PK, Kuluski K, Cott C. The electronic patient reported outcome Tool: testing usability and feasibility of a mobile app and portal to support care for patients with complex chronic disease and disability in primary care settings. JMIR mHealth uHealth 2016 Jun 02;4(2):e58 [FREE Full text] [doi: 10.2196/mhealth.5331] [Medline: 27256035]

26. Schweitzer J, Synowiec C. The economics of eHealth and mHealth. J Health Commun 2012;17(Suppl 1):73-81. [doi: 10.1080/10810730.2011.649158] [Medline: 22548602]

27. Currie M, Philip LJ, Roberts A. Attitudes towards the use and acceptance of eHealth technologies: a case study of older adults living with chronic pain and implications for rural healthcare. BMC Health Serv Res 2015 Apr 16;15:162 [FREE Full text] [doi: 10.1186/s12913-015-0825-0] [Medline: 25888988]

28. Government Offices of Sweden and Swedish Association of Local Authorities and Regions. Vision for eHealth 2025 common starting points for digitisation of social services and health care (Vision e-hälsa 2025 - gemensamma utgångspunkter för digitalisering i socialtjänst och hälso- och sjukvård). Ministry of Health and Social Affairs \& Swedish Association of Local Authorities and Regions (Socialdepartementet \& Sveriges Kommuner och Landsting) 2016 URL: https://www. ehalsomyndigheten.se/globalassets/dokument/vision/vision-for-ehealth-2025.pdf [accessed 2018-02-20] [WebCite Cache ID 6xMLI8Fay]

29. Gund A, Lindecrantz K, Schaufelberger M, Patel H, Sjöqvist BA. Attitudes among healthcare professionals towards ICT and home follow-up in chronic heart failure care. BMC Med Inform Decis Mak 2012 Nov 28;12:138 [FREE Full text] [doi: 10.1186/1472-6947-12-138] [Medline: 23190602]

30. Wildevuur SE, Simonse LW. Information and communication technology-enabled person-centered care for the "big five" chronic conditions: scoping review. J Med Internet Res 2015 Mar 27;17(3):e77 [FREE Full text] [doi: 10.2196/jmir.3687] [Medline: 25831199]

31. Ekman I, Swedberg K, Taft C, Lindseth A, Norberg A, Brink E, et al. Person-centered care--ready for prime time. Eur J Cardiovasc Nurs 2011 Dec;10(4):248-251. [doi: 10.1016/j.ejcnurse.2011.06.008] [Medline: 21764386]

32. Gordon NP, Hornbrook MC. Differences in access to and preferences for using patient portals and other eHealth technologies based on race, ethnicity, and age: a database and survey study of seniors in a large health plan. J Med Internet Res 2016 Mar 04;18(3):e50 [FREE Full text] [doi: 10.2196/jmir.5105] [Medline: 26944212] 
33. Kontos E, Blake KD, Chou WY, Prestin A. Predictors of eHealth usage: insights on the digital divide from the Health Information National Trends Survey 2012. J Med Internet Res 2014;16(7):e172 [FREE Full text] [doi: 10.2196/jmir.3117] [Medline: 25048379]

34. Nijland N, van Gemert-Pijnen JE, Kelders SM, Brandenburg BJ, Seydel ER. Factors influencing the use of a Web-based application for supporting the self-care of patients with type 2 diabetes: a longitudinal study. J Med Internet Res 2011;13(3):e71 [FREE Full text] [doi: 10.2196/jmir.1603] [Medline: 21959968]

35. Huygens MW, Vermeulen J, Swinkels IC, Friele RD, van Schayck OC, de Witte LP. Expectations and needs of patients with a chronic disease toward self-management and eHealth for self-management purposes. BMC Health Serv Res 2016 Jul 08;16:232 [FREE Full text] [doi: 10.1186/s12913-016-1484-5] [Medline: 27391471]

36. Graneheim UH, Lundman B. Qualitative content analysis in nursing research: concepts, procedures and measures to achieve trustworthiness. Nurse Educ Today 2004 Feb;24(2):105-112. [doi: 10.1016/j.nedt.2003.10.001] [Medline: 14769454]

37. Krippendorff K. Content Analysis: An Introduction to Its Methodology. United Kingdom: SAGE Publications Inc; 2003.

38. Mishler EG. The analysis of interview-narratives. In: Sarbin TR, editor. Narrative Psychology: The Storied Nature of Human Conduct. Westport, CT, US: Praeger Publishers Inc; 1986:233-255.

39. Graneheim UH, Lindgren BM, Lundman B. Methodological challenges in qualitative content analysis: a discussion paper. Nurse Educ Today 2017 Sep;56:29-34. [doi: 10.1016/j.nedt.2017.06.002] [Medline: 28651100]

40. World Medical Association. World medical association declaration of Helsinki: ethical principles for medical research involving human subjects. J Am Med Assoc 2013 Nov 27;310(20):2191-2194. [doi: 10.1001/jama.2013.281053] [Medline: 24141714]

41. Zulman DM, Jenchura EC, Cohen DM, Lewis ET, Houston TK, Asch SM. How can eHealth technology address challenges related to multimorbidity? Perspectives from patients with multiple chronic conditions. J Gen Intern Med 2015 Aug;30(8):1063-1070 [FREE Full text] [doi: 10.1007/s11606-015-3222-9] [Medline: 25691239]

42. Nijland N, van Gemert-Pijnen JE, Kelders SM, Brandenburg BJ, Seydel ER. Factors influencing the use of a Web-based application for supporting the self-care of patients with type 2 diabetes: a longitudinal study. J Med Internet Res 2011;13(3):e71 [FREE Full text] [doi: 10.2196/jmir.1603] [Medline: 21959968]

43. Verhoeven F, Tanja-Dijkstra K, Nijland N, Eysenbach G, van Gemert-Pijnen L. Asynchronous and synchronous teleconsultation for diabetes care: a systematic literature review. J Diabetes Sci Technol 2010 May;4(3):666-684 [FREE Full text] [Medline: 20513335]

44. Alpay LL, Henkemans OB, Otten W, Rövekamp TA, Dumay AC. E-health applications and services for patient empowerment: directions for best practices in The Netherlands. Telemed J E Health 2010 Sep;16(7):787-791. [doi: 10.1089/tmj.2009.0156] [Medline: 20815745]

45. Holtz B, Lauckner C. Diabetes management via mobile phones: a systematic review. Telemed J E Health 2012 Apr;18(3):175-184. [doi: 10.1089/tmj.2011.0119] [Medline: 22356525]

46. Alvarado MM, Kum HC, Gonzalez Coronado K, Foster MJ, Ortega P, Lawley MA. Barriers to remote health interventions for type 2 diabetes: a systematic review and proposed classification scheme. J Med Internet Res 2017 Feb 13;19(2):e28. [doi: 10.2196/jmir.6382] [Medline: 28193598]

47. Kruis AL, van Schayck OC, in't Veen JC, van der Molen T, Chavannes NH. Successful patient self-management of COPD requires hands-on guidance. Lancet Respir Med 2013 Nov;1(9):670-672. [doi: 10.1016/S2213-2600(13)70212-1] [Medline: 24429261]

48. Ahern DK, Woods SS, Lightowler MC, Finley SW, Houston TK. Promise of and potential for patient-facing technologies to enable meaningful use. Am J Prev Med 2011 May;40(5 Suppl 2):S162-S172. [doi: 10.1016/j.amepre.2011.01.005] [Medline: 21521591]

49. Kuijpers W, Groen WG, Aaronson NK, van Harten WH. A systematic review of web-based interventions for patient empowerment and physical activity in chronic diseases: relevance for cancer survivors. J Med Internet Res 2013;15(2):e37 [FREE Full text] [doi: 10.2196/jmir.2281] [Medline: 23425685]

50. Serrano-Gil M, Jacob S. Engaging and empowering patients to manage their type 2 diabetes, part I: a knowledge, attitude, and practice gap? Adv Ther 2010 Jun;27(6):321-333. [doi: 10.1007/s12325-010-0034-5] [Medline: 20552306]

51. Stellefson M, Chaney B, Barry AE, Chavarria E, Tennant B, Walsh-Childers K, et al. Web 2.0 chronic disease self-management for older adults: a systematic review. J Med Internet Res 2013 Feb 14;15(2):e35 [FREE Full text] [doi: 10.2196/jmir.2439] [Medline: 23410671]

52. Holmström I, Röing M. The relation between patient-centeredness and patient empowerment: a discussion on concepts. Patient Educ Couns 2010 May;79(2):167-172. [doi: 10.1016/j.pec.2009.08.008] [Medline: 19748203]

53. Olsson L, Jakobsson Ung E, Swedberg K, Ekman I. Efficacy of person-centred care as an intervention in controlled trials - a systematic review. J Clin Nurs 2013 Feb;22(3-4):456-465. [doi: 10.1111/jocn.12039] [Medline: 23231540]

54. Ekman I, Wolf A, Olsson LE, Taft C, Dudas K, Schaufelberger M, et al. Effects of person-centred care in patients with chronic heart failure: the PCC-HF study. Eur Heart J 2012 May;33(9):1112-1119 [FREE Full text] [doi: 10.1093/eurheartj/ehr306] [Medline: 21926072] 
55. Jutterström L, Hörnsten $\AA$, Sandström H, Stenlund H, Isaksson U. Nurse-led patient-centered self-management support improves HbA1c in patients with type 2 diabetes-a randomized study. Patient Educ Couns 2016 Nov;99(11):1821-1829. [doi: 10.1016/j.pec.2016.06.016] [Medline: 27372525]

56. Graffigna G, Barello S, Bonanomi A, Menichetti J. The motivating function of healthcare professional in eHealth and mHealth interventions for type 2 diabetes patients and the mediating role of patient engagement. J Diabetes Res 2016;2016:2974521 [FREE Full text] [doi: 10.1155/2016/2974521] [Medline: 26881243]

57. Salvador-Carulla L, Cloninger CR, Thornicroft A, Mezzich JE, 2013 Geneva Declaration Consultation Group. Background, structure and priorities of the 2013 Geneva declaration on person-centered health research. Int J Pers Cent Med 2013;3(2):109-113 [FREE Full text] [doi: 10.5750/ijpcm.v3i2.401] [Medline: 26146541]

58. Gupta D, Denton B. Appointment scheduling in health care: challenges and opportunities. IIE Trans 2008 Jul 21;40(9):800-819. [doi: 10.1080/07408170802165880]

59. Ho K, Newton L, Boothe A, Novak-Lauscher H. mobile Digital Access to a Web-enhanced Network (mDAWN): assessing the feasibility of mobile health tools for self-management of type-2 diabetes. AMIA Annu Symp Proc 2015;2015:621-629 [FREE Full text] [Medline: 26958197]

60. Gagnon MP, Desmartis M, Labrecque M, Car J, Pagliari C, Pluye P, et al. Systematic review of factors influencing the adoption of information and communication technologies by healthcare professionals. J Med Syst 2012 Feb;36(1):241-277 [FREE Full text] [doi: 10.1007/s10916-010-9473-4] [Medline: 20703721]

61. Black AD, Car J, Pagliari C, Anandan C, Cresswell K, Bokun T, et al. The impact of eHealth on the quality and safety of health care: a systematic overview. PLoS Med 2011 Jan 18;8(1):e1000387 [FREE Full text] [doi: 10.1371/journal.pmed.1000387] [Medline: 21267058]

62. Scandurra I, Hägglund M, Persson A, Ahlfeldt RM. Disturbing or facilitating?--on the usability of Swedish eHealth systems 2013. Stud Health Technol Inform 2014;205:221-225. [Medline: 25160178]

63. Spanakis EG, Chiarugi F, Kouroubali A, Spat S, Beck P, Asanin S, et al. Diabetes management using modern information and communication technologies and new care models. Interact J Med Res 2012 Oct 04;1(2):e8 [FREE Full text] [doi: 10.2196/ijmr.2193] [Medline: 23612026]

64. Harno K, Kauppinen-Mäkelin R, Syrjäläinen J. Managing diabetes care using an integrated regional e-health approach. J Telemed Telecare 2006;12(Suppl 1):13-15. [doi: 10.1258/135763306777978380] [Medline: 16884565 ]

65. Eland-de Kok P, van Os-Medendorp H, Vergouwe-Meijer A, Bruijnzeel-Koomen C, Ros W. A systematic review of the effects of e-health on chronically ill patients. J Clin Nurs 2011 Nov;20(21-22):2997-3010. [doi:

10.1111/j.1365-2702.2011.03743.x] [Medline: 21707807]

66. Hardiker NR, Grant MJ. Factors that influence public engagement with eHealth: a literature review. Int J Med Inform 2011 Jan;80(1):1-12. [doi: 10.1016/j.ijmedinf.2010.10.017] [Medline: 21112244]

67. Czaja SJ, Lee CC. The impact of aging on access to technology. Univ Access Inf Soc 2006 Dec 8;5(4):341-349. [doi: 10.1007/s10209-006-0060-x]

68. Norman CD, Skinner HA. eHealth literacy: essential skills for consumer health in a networked world. J Med Internet Res 2006 Jun 16;8(2):e9 [FREE Full text] [doi: 10.2196/jmir.8.2.e9] [Medline: 16867972]

69. Johansson AM, Lindberg I, Söderberg S. Patients' experiences with specialist care via video consultation in primary healthcare in rural areas. Int J Telemed Appl 2014;2014:143824 [FREE Full text] [doi: 10.1155/2014/143824] [Medline: 25243009]

70. Wälivaara BM, Andersson S, Axelsson K. Views on technology among people in need of health care at home. Int $\mathbf{J}$ Circumpolar Health 2009 Apr;68(2):158-169. [Medline: 19517875]

71. Zickuhr K, Smith A. Pew Internet. Digital differences URL: http://www.pewinternet.org/Reports/2012/Digital-differences. aspx[WebCite Cache ID 6AfwRrCZJ]

72. Berland GK, Elliott MN, Morales LS, Algazy JI, Kravitz RL, Broder MS, et al. Health information on the internet: accessibility, quality, and readability in English and Spanish. J Am Med Assoc 2001;285(20):2612-2621 [FREE Full text] [Medline: 11368735]

73. Statistiska Centralbyrån. : Statistics Sweden (Statistiska centralbyrån, SCB) Use of computers and the internet by private persons in 2016 (Privatpersoners användning av datorer och internet 2016) URL: https://www.scb.se/Statistik/ Publikationer/ LE0108_2016A01_BR_00_IT01BR1601.pdf [accessed 2018-02-19] [WebCite Cache ID 6xMS4PU9V]

74. Fuji KT, Abbott AA, Galt KA. A qualitative study of how patients with type 2 diabetes use an electronic stand-alone personal health record. Telemed J E Health 2015 Apr;21(4):296-300 [FREE Full text] [doi: 10.1089/tmj.2014.0084] [Medline: 25614996]

75. Creswell JW. Qualitative Inquiry and Research Design: Choosing Among Five Approaches. Thousand Oaks, CA: SAGE Publications, Inc; 2012.

76. Polit DF, Beck CT. Essentials of Nursing Research: Appraising Evidence for Nursing Practice. Philadelphia, USA, Wolters Kluwer Health: Lippincott Williams \& Wilkins; 2010. 


\section{Abbreviations}

eHealth: electronic health

ICT: information and communication technology

iSMS: interactive self-management support

PCC: person-centered care

SOS: socioeconomic status

T2D: type 2 diabetes

Edited by G Eysenbach; submitted 02.10.17; peer-reviewed by E Da Silva, K Pal, N Chavannes; comments to author 10.12.17; revised version received 27.12.17; accepted 26.01.18; published 12.03.18

Please cite as:

Öberg U, Isaksson U, Jutterström L, Orre CJ, Hörnsten A

Perceptions of Persons With Type 2 Diabetes Treated in Swedish Primary Health Care: Qualitative Study on Using eHealth Services for Self-Management Support

JMIR Diabetes 2018;3(1):e7

URL: http://diabetes.jmir.org/2018/1/e7/

doi: $10.2196 /$ diabetes. 9059

PMID: 30291075

(CUlrika Öberg, Ulf Isaksson, Lena Jutterström, Carl Johan Orre, Åsa Hörnsten. Originally published in JMIR Diabetes (http://diabetes.jmir.org), 12.03.2018. This is an open-access article distributed under the terms of the Creative Commons Attribution License (https://creativecommons.org/licenses/by/4.0/), which permits unrestricted use, distribution, and reproduction in any medium, provided the original work, first published in JMIR Diabetes, is properly cited. The complete bibliographic information, a link to the original publication on http://diabetes.jmir.org/, as well as this copyright and license information must be included. 